\title{
Clinical and Epidemiologic Features of Diarrheal Disease due to Aeromonas hydrophila and Plesiomonas shigelloides Infections Compared with Those due to Vibrio cholerae Non-O1 and Vibrio parahaemolyticus in Bangladesh
}

\author{
Erik H. Klontz, ${ }^{1}$ Abu S. G. Faruque,, ${ }^{2}$ Sumon K. Das, ${ }^{2}$ Mohammed A. Malek, ${ }^{2}$ Zhahirul Islam, $^{2}$ \\ Stephen P. Luby, ${ }^{2,3}$ and Karl C. Klontz ${ }^{4}$ \\ ${ }^{1}$ Carleton College, One North College Street, Northfield, MN 55057, USA \\ ${ }^{2}$ International Centre for Diarrhoeal Disease Research, Bangladesh (icddr,b), Dhaka, Bangladesh \\ ${ }^{3}$ Centers for Disease Control and Prevention, Atlanta, GA, USA \\ ${ }^{4}$ Office of Food Defense, Communications, and Emergency Response, Center for Food Safety and Applied Nutrition, \\ Food and Drug Administration, 5100 Paint Branch Parkway, College Park, MD 20740, USA
}

Correspondence should be addressed to Karl C. Klontz, karl.klontz@fda.hhs.gov

Received 31 July 2012; Accepted 26 August 2012

Academic Editors: H. I. Atabay, A. Latifi, and J. Theron

Copyright (C) 2012 Erik H. Klontz et al. This is an open access article distributed under the Creative Commons Attribution License, which permits unrestricted use, distribution, and reproduction in any medium, provided the original work is properly cited.

\begin{abstract}
Using data from the International Centre for Diarrhoeal Disease Research, Bangladesh (icddr,b) from 1996 to 2001, we compared the clinical features of diarrhea in patients with stool specimens yielding only A. hydrophila (189 patients; $1.4 \%$ of 13,970 patients screened) or $P$. shigelloides (253 patients) compared to patients with sole V. cholerae non-O1 infection (99 patients) or $V$. parahaemolyticus infection (126 patients). Patients exhibited similar frequencies of fever (temperature $>37.8^{\circ} \mathrm{C}$ ), stools characterized as watery, and stools containing visible mucus. Dehydration was observed more often among patients with $V$. parahaemolyticus or $V$. cholerae non-O1 infection. Compared to patients infected with V. parahaemolyticus, those with A. hydrophila, P. shigelloides, or V. cholerae non-O1 infection were less likely to report visible blood in the stool and, on microscopic examination, less likely to exhibit stool red blood cell and white blood cell counts exceeding 20 cells per high power field. The proportion of patients reporting subjective cure at the time of discharge was significantly smaller for those infected with $V$. parahaemolyticus. These findings suggest that $A$. hydrophila and $P$. shigelloides produce diarrheal disease that is less severe than that resulting from infection with V. cholerae non-O1 or V. parahaemolyticus.
\end{abstract}

\section{Introduction}

Aeromonas hydrophila and Plesiomonas shigelloides are Gramnegative bacilli within the families Aeromonadaceae and Enterobacteriaceae, respectively. Although the two bacteria occupy separate taxonomic niches, they share attributes in being widely distributed in freshwater, estuarine, and marine environments, and both have been recognized to cause systemic infection in immunocompromised hosts and to be possible causes of diarrheal disease $[1,2]$. Water and food serve as vehicles of transmission for both pathogens [1].
At present, aeromonads are not universally accepted as true enteropathogens [1]. While some reports have ascribed [3] or refuted [4] an etiologic role to aeromonads in diarrheal disease, others $[5,6]$ have postulated that only certain subsets of aeromonads equipped with genes for enterotoxicity are significantly associated with diarrhea. Several factors have contributed to uncertainty regarding the enteropathogenicity of aeromonads: the lack of recognized outbreaks with clonally distinct isolates recovered from patients and an implicated source [1]; infrequent documentation of personto-person transmission; a paucity of evidence demonstrating 
experimental pathogenicity in humans [7]; absence of a good animal model to carry out infection studies [6]; in some reports, overlapping prevalence of aeromonads in patients with diarrhea compared to asymptomatic individuals [8]. In contrast, $P$. shigelloides has been identified as the cause of outbreaks of diarrheal disease $[9,10]$ and is known to play an etiologic role in travelers' diarrhea [11], dysentery [12], and diarrhea in pediatric [13] and adult [14] outpatients.

Relatively few studies have compared the clinical features of diarrheal illness produced by A. hydrophila and P. shigelloides with those of more established enteric pathogens [15, 16]. Such a comparison conducted in a region with a large number of illnesses could offer insight into clinical nuances associated with each agent. Accordingly, we compared the clinical features of diarrheal disease in persons infected solely with A. hydrophila or P. shigelloides with those in persons infected solely with Vibrio cholerae non-O1 or Vibrio parahaemolyticus. We chose the latter pathogens for comparison because, like A. hydrophila and P. shigelloides, both are transmitted by food and water [17], infect a wide age spectrum of persons [18], and were shown to be prevalent in our study population, patients treated at the International Centre for Diarrhoeal Disease Research in Dhaka, Bangladesh (icddr,b).

\section{Methods}

For over four decades, the International Centre for Diarrhoeal Disease Research in Bangladesh has addressed leading health-related problems through patient care, collaborative research, and extension activities. As a component of its surveillance activities, in 1979, the Centre initiated a systematic sampling program wherein every 25 th patient presenting to icddr,b with diarrheal disease was studied in detail for the microbiologic etiology of illness. Employing standard microbiologic procedures [19], from 1996 through 2001, diarrheal stools were tested routinely for $A$. hydrophila and $P$. shigelloides in addition to Salmonella, Shigella, Vibrio cholera O1, V. parahaemolyticus, V. cholerae non-O1, other Vibrios, E. coli (enterotoxigenic, enteropathogenic, enteroaggregative, enteroinvasive, and Shiga-toxin-producing), Campylobacter, rotavirus, Entamoeba, Giardia, and Cryptosporidium.

Aeromonads were identified using standard bacteriological procedures [20]. Stool samples specifically were enriched in bile broth and subcultured onto taurocholate-telluritegelatin agar (TTGA). Transparent oxidase-positive presumptive colonies were tested with Vibrio polyvalent and Vibrio 0139 antisera, and those that tested negative were identified further based on sugar fermentation, amino acid content, and ability to grow in broth of varying salt concentrations. Isolates were identified as A. hydrophila based on sugar fermentation results (esculin, salicin, arabinose, mannitol, sucrose, and inositol), amino acid content (arginine, lysine, and ornithine), and ability to grow in broth of varying sodium chloride concentrations $(0 \%, 6.5 \%$, or $8 \%)$. Further characterization of isolates was undertaken using vibriostatic compound disc $0129(150 \mu \mathrm{g})$ and the Analytical Profile Index (API), as necessary.
We analyzed microbiologic results for the period 1996 through 2001 along with select responses to a standard questionnaire administered to patients with diarrheal disease diagnosed and treated at icddr,b during the same period. Among other items, the questionnaire solicited information regarding demographics, clinical features of illness, and microscopic evaluation of diarrheal specimens. Pairwise assessments of responses for patients infected with $A$. hydrophila or P. shigelloides were compared with those for patients infected with $V$. cholera non-O1 or $V$. parahaemolyticus using a chi-square or Fisher's exact test to assess differences of statistical significance $(P$ value $<0.05)$. We hypothesized that if $A$. hydrophila and $P$. shigelloides were enteropathogens, responses for patients with diarrheal disease from whom these two organisms were recovered from stool specimens would be similar to responses from persons infected with $V$. cholerae non-O1 or V. parahaemolyticus. For a variable called "outcome" in the questionnaire, patients were asked to specify subjectively whether they felt "cured" prior to discharge or whether the illness was "continuing."

Using daily temperature and rainfall data for Dhaka for the entire study period obtained from the Government of People's Republic of Bangladesh, Bangladesh Meteorological Department (Climate Division), we assessed correlations between total monthly rainfall and mean monthly temperature with the number of patients treated at icddr,b from whom a stool culture yielded only one of the following enteric pathogens: Aeromonas hydrophila, Plesiomonas shigelloides, Vibrio cholerae non-O1, or Vibrio parahaemolyticus; correlations were calculated using a threshold for statistical significance defined by a $P$ value of less than 0.05 .

\section{Results}

From 1996 through 2001, stool specimens were collected from 13,970 patients with diarrheal disease for assessment of the pathogens listed above. Among these patients, A. hydrophila was the sole organism recovered from 189 (1.4\%) patients, $P$. shigelloides from $253(1.8 \%)$ patients, V. cholerae non-O1 from 99 patients $(0.7 \%)$, and $V$. parahaemolyticus from $126(0.9 \%)$ patients. The majority of patients were males (Table 1). Patients with A. hydrophila infection were younger than those infected by $P$. shigelloides, $V$. cholerae non$\mathrm{O} 1$, or $V$. parahaemolyticus infections.

Patients with all four types of infections exhibited similar frequencies of fever (temperature $>37.8^{\circ} \mathrm{C}$ ), stools characterized as watery, stools containing visible mucus, maximum number of stools per 24 hours, and duration of illness (Table 1). On the other hand, dehydration was observed more often among patients with $V$. cholerae non-O1 or $V$. parahaemolyticus infection, both groups of which received intravenous rehydration more often than did patients from whom A. hydrophila or P. shigelloides was recovered. In general, patients from whom $V$. parahaemolyticus was recovered experienced the most severe infections as evidenced by the higher frequency of vomiting and production of stools with visible blood, and the higher percentage of stool specimens for which red or white blood cell counts exceeded 20 cells 


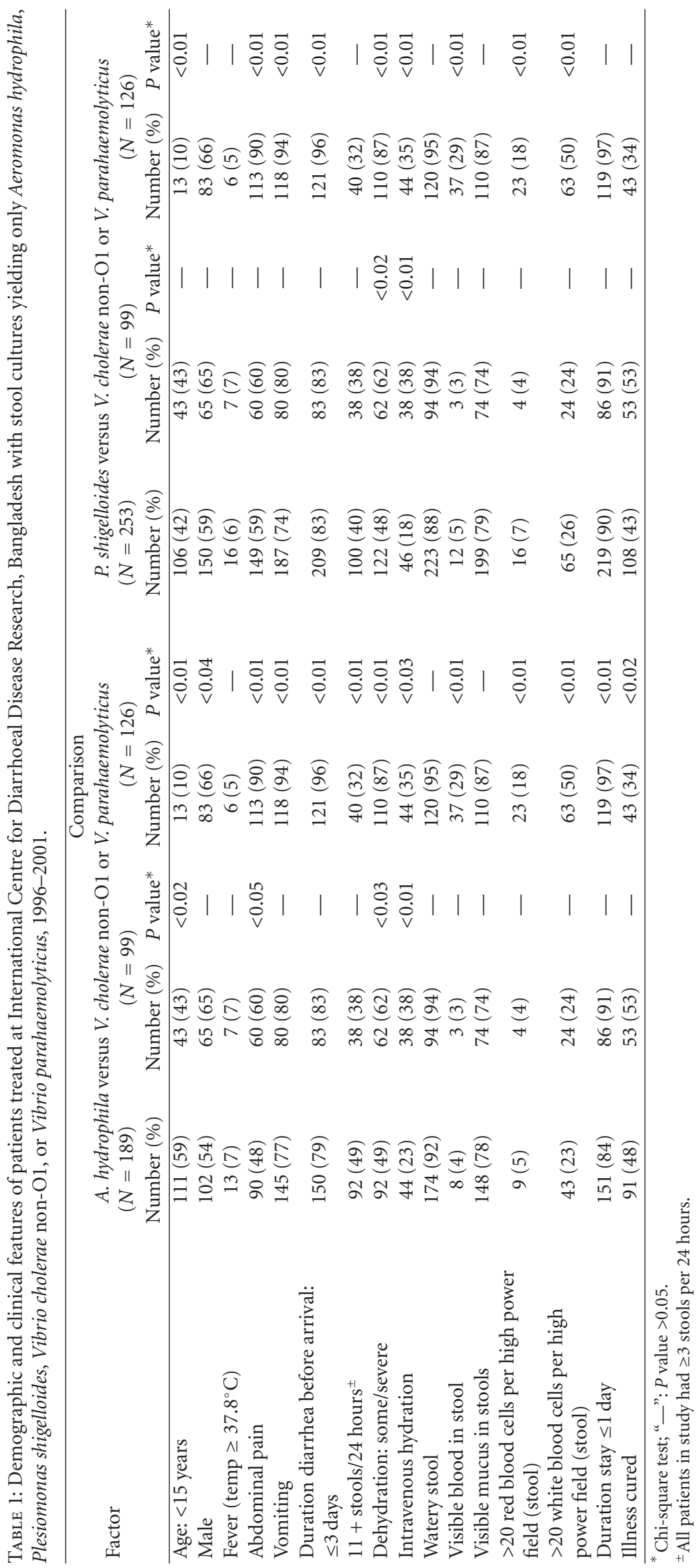




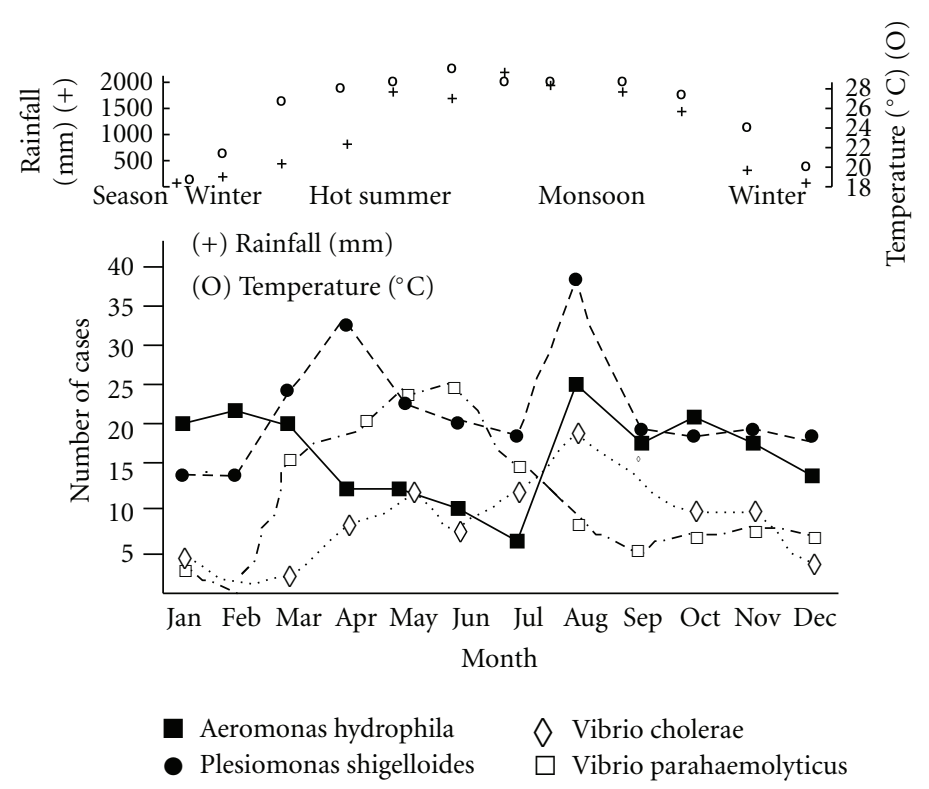

Figure 1: Number of Aeromonas hydrophila, Plesiomonas shigelloides, Vibrio cholerae non-O1, and Vibrio parahaemolyticus infections, and mean temperature and total rainfall, by month, International Centre for Diarrhoeal Disease Research, Bangladesh, 1996-2001.

TABLE 2: Correlation coefficients for total monthly rainfall and mean monthly temperature by total number of sole infections per month due to Aeromonas hydrophila, Plesiomonas shigelloides, Vibrio cholerae non-O1, or Vibrio parahaemolyticus, International Center for Diarrhoeal Disease Research, Bangladesh, 1996-2001.

\begin{tabular}{lcccccccc}
\hline & \multicolumn{4}{c}{ Infection } & \multicolumn{4}{c}{ V } \\
Variable & Aeromonas hydrophila & Plesiomonas shigelloides & \multicolumn{2}{c}{ Vibrio cholerae non-O1 } & \multicolumn{2}{c}{ Vibrio parahaemolyticus } \\
& $r$ & $P$ value & $r$ & $P$ value & $r$ & $P$ value & $r$ & $P$ value \\
\hline Total monthly rainfall & -0.245 & 0.44 & 0.394 & 0.21 & 0.858 & $<0.01$ & 0.397 & 0.20 \\
Mean monthly temperature & -0.257 & 0.42 & 0.542 & 0.07 & 0.785 & $<0.01$ & 0.604 & $<0.05$ \\
\hline
\end{tabular}

per high power field; in addition, patients infected with $V$. parahaemolyticus were less likely than their counterparts to report a subjective sense of being cured at the time of discharge.

Although pathogens were isolated throughout the year, the monthly number of infections peaked in August for $A$. hydrophila, P. shigelloides, and V. cholerae non-O1 (Figure 1). The number of infections with $V$. cholerae non-O1 was correlated directly with total monthly rainfall and mean monthly temperature, while the number of $V$. parahaemolyticus infections was correlated with mean monthly temperature (Table 2); no significant correlations were observed with either meteorological variable and A. hydrophila or $P$. shigelloides.

\section{Discussion}

In Bangladesh, patients with diarrhea severe enough to require hospitalization were occasionally infected with $A$. hydrophila or P. shigelloides. Clinically, these patients shared a number of features with those infected with $V$. cholerae non$\mathrm{O} 1$ or $V$. parahaemolyticus. For example, fever (temperature $>37.8^{\circ} \mathrm{C}$ ) was rare, mucus was frequently visible in stools, a similar maximum number of stools per 24 hours was reported, and the duration of illness was similar. Moreover, patients infected with A. hydrophila, P. shigelloides, and V. cholerae non-O1 were similar in terms of the frequency with which $>20$ red blood cells or white blood cells were present per high field on stool examination, as well as in terms of the subjective proportions who deemed themselves to be cured at the time of discharge.

On the other hand, there appeared to be a gradation of severity such that patients infected with A. hydrophila or $P$. shigelloides experienced the least severe illness, while the severity of infection was somewhat greater for $V$. cholera nonO1-infected individuals, and most severe for patients with $V$. parahaemolyticus infection. While a greater proportion of patients with the four infections we studied were males, a finding similar to a report describing Shigella infections in Bangladesh [21], those infected with A. hydrophila were significantly younger than their counterparts.

Otherwise, with regard to the visibility of mucus or blood in stools and the presence of $>20$ red blood cells or white blood cells per high power field, patients infected with $A$. hydrophila and P. shigelloides resembled those infected with $V$. cholera non-O1. Moreover, the proportion of patients whose infections were deemed to have been cured was similar for 
these three groups. However, intravenous hydration as an added component to oral rehydration therapy was used less often among patients with $A$. hydrophila or P. shigelloides infections compared to those infected with the Vibrios.

In light of our findings that patients infected with $A$. hydrophila or P. shigelloides displayed clinical features that were, in large part, similar to those infected with $V$. cholera non-O1, an organism recognized as a true enteropathogen, we believe there is reason to ascribe a causative role for A. hydrophila in diarrheal disease. As others have stated $[1,6]$, certain strains of $A$. hydrophila likely possess genetic attributes that facilitate the production of a secretory diarrhea in susceptible individuals. Supporting this concept was a study of the distribution of $A$. hydrophila enterotoxins Alt, Ast, and Act in children with and without diarrhea in Bangladesh [22]; the number of isolates positive for both the alt and ast genes was significantly higher for diarrheal children than for control children, suggesting the enterotoxins produced by the two genes may act synergistically to induce severe diarrhea. Our results corroborate a role for $P$. shigelloides as an etiologic agent of diarrhea as well, an organism that has been associated with outbreaks of diarrhea $[9,10]$ and, in addition, has been shown to elaborate an enterotoxin that causes elongation of Chinese hamster ovary cells by activating adenylate cyclase with a resulting increase in cyclic AMP, a sequence of physiologic events characteristic of enterotoxins produced by Vibrio cholerae and enterotoxigenic E. coli [23].

We observed several differences in the epidemiology of the four pathogens assessed here. Whereas A. hydrophila, $P$. shigelloides, and $V$. cholerae non-O1 infections were diagnosed commonly in infants, $V$. parahaemolyticus infections were distinctly uncommon in this age group, being most often diagnosed in persons aged 15-44 years, a pattern described for $V$. parahaemolyticus cases in Canada as well [24]. The pathogens exhibited divergences in terms of seasonal occurrence too, with no correlation seen between rainfall and temperature with either A. hydrophila or $P$. shigelloides infections. In contrast, both $V$. cholerae non-O1 and V. parahaemolyticus were correlated with temperature, and $V$. cholerae non-O1 was correlated with rainfall as well. The lack of an observed correlation between A. hydrophila and $P$. shigelloides with either rainfall or temperature differs from the results of several other studies. For example, increased recoveries of Aeromonas from stool specimens have often been reported during warmer months, a time when concentrations of mesophilic organisms may increase in aquatic environments [1]. In an investigation of a waterborne outbreak of $P$. shigelloides infections in Japan, investigators reported that the recovery of $P$. shigelloides from environmental samples, and mud in particular, was most common during the warmer months [9]. It is possible that absence of a correlation between A. hydrophila and $P$. shigelloides infections with either rainfall or temperature in Bangladesh is a result of conditions characteristic of Bangladesh, including climatic, geographic, socioeconomic, sanitary, and host factors.

A limitation of the present study was that not all known microbial causes of diarrhea were assessed in patients presenting to icddr,b from 1996 to 2001. Thus, it is possible that pathogens other than those screened were, in fact, responsible for a proportion of cases attributed to $A$. hydrophila and P. shigelloides. However, if this was the case, the same limitation might apply to patients from whom $V$. cholerae non-O1 or $V$. parahaemolyticus were recovered in pure culture. Arguing against this possibility are clinical and epidemiologic features described here that parallel findings from previous investigations of these two Vibrios [15, 24, 25]. Thus, if a substantial number of the illnesses described here were truly sole infections, our paper adds to the evidence of $P$. shigelloides being a cause of diarrhea and strengthens the hypothesis that certain strains of $A$. hydrophila may be true enteropathogens as well.

\section{Acknowledgments}

Hospital surveillance was funded by the International Centre for Diarrhoeal Disease Research, Bangladesh (icddr,b) and the Government of the People's Republic of Bangladesh through IHP-HNPRP. The International Centre for Diarrhoeal Disease Research, Bangladesh acknowledges with gratitude the commitment of the Government of the People's Republic of Bangladesh to the Centre's research efforts and also gratefully acknowledges the following donors which provide unrestricted support to the Centre's research efforts: Australian Agency for International Development (AusAID), Government of the People's Republic of Bangladesh, Canadian International Development Agency (CIDA), Embassy of the Kingdom of the Netherlands (EKN), Swedish International Development Cooperation Agency (Sida), Swiss Agency for Development and Cooperation (SDC), and Department for International Development, UK (DFID).

\section{References}

[1] J. M. Janda and S. L. Abbott, "The genus Aeromonas: taxonomy, pathogenicity, and infection," Clinical Microbiology Reviews, vol. 23, no. 1, pp. 35-73, 2010.

[2] R. A. Brenden, M. A. Miller, and J. M. Janda, "Clinical disease spectrum and pathogenic factors associated with Plesiomonas shigelloides infections in humans," Reviews of Infectious Diseases, vol. 10, no. 2, pp. 303-316, 1988.

[3] B. Svenungsson, A. Lagergren, E. Ekwall et al., "Enteropathogens in adult patients with diarrhea and healthy control subjects: a 1-year prospective study in a Swedish clinic for infectious diseases," Clinical Infectious Diseases, vol. 30, no. 5, pp. 770-778, 2000.

[4] Y. W. Chu, C. H. Wong, G. K. L. Tsang et al., "Lack of association between presentation of diarrhoeal symptoms and faecal isolation of Aeromonas spp. amongst outpatients in Hong Kong," Journal of Medical Microbiology, vol. 55, no. 3, pp. 349-351, 2006.

[5] A. von Graevenitz, "The role of Aeromonas in diarrhea: a review," Infection, vol. 35, no. 2, pp. 59-64, 2007.

[6] J. L. Parker and J. G. Shaw, "Aeromonas spp. clinical microbiology and disease," Journal of Infection, vol. 62, no. 2, pp. 109-118, 2011.

[7] D. R. Morgan, P. C. Johnson, H. L. DuPont, T. K. Satterwhite, and L. V. Wood, "Lack of correlation between known virulence 
properties of Aeromonas hydrophila and enteropathogenicity for humans," Infection and Immunity, vol. 50, no. 1, pp. 62-65, 1985.

[8] S. D. Holmberg and J. J. Farmer III, "Aeromonas hydrophila and Plesiomonas shigelloides as causes of intestinal infections," Reviews of Infectious Diseases, vol. 6, no. 5, pp. 633-639, 1984.

[9] T. Tsukamoto, Y. Kinoshita, T. Shimada, and R. Sakazaki, “Two epidemics of diarrhoeal disease possibly caused by Plesiomonas shigelloides," Journal of Hygiene, vol. 80, no. 2, pp. 275-280, 1978.

[10] M. Wouafo, R. Pouillot, P. F. Kwetche, M. C. Tejiokem, J. Kamgno, and M. C. Fonkoua, "An acute foodborne outbreak due to Plesiomonas shigelloides in Yaounde, Cameroon," Foodborne Pathogens and Disease, vol. 3, no. 2, pp. 209-211, 2006.

[11] N. Shah, H. L. DuPont, and D. J. Ramsey, "Global etiology of travelers' diarrhea: systematic review from 1973 to the present," American Journal of Tropical Medicine and Hygiene, vol. 80, no. 4, pp. 609-614, 2009.

[12] M. L. Pfeiffer, H. L. DuPont, and T. J. Ochoa, "The patient presenting with acute dysentery-a systematic review," Journal of Infection, vol. 64, pp. 374-386, 2012.

[13] A. M. Khan, A. S. G. Faruque, M. S. Hossain, S. Sattar, G. J. Fuchs, and M. A. Salam, "Plesiomonas shigelloidesassociated diarrhoea in Bangladeshi children: a hospital-based surveillance study," Journal of Tropical Pediatrics, vol. 50, no. 6, pp. 354-356, 2004.

[14] S. S. W. Chan, K. C. Ng, D. J. Lyon, W. L. Cheung, A. F. B. Cheng, and T. H. Rainer, "Acute bacterial gastroenteritis: a study of adult patients with positive stool cultures treated in the emergency department," Emergency Medicine Journal, vol. 20, no. 4, pp. 335-338, 2003.

[15] K. C. Kain and M. T. Kelly, "Clinical features, epidemiology, and treatment of Plesiomonas shigelloides diarrhea," Journal of Clinical Microbiology, vol. 27, no. 5, pp. 998-1001, 1989.

[16] I. A. Mikhail, E. Fox, R. L. Haberberger Jr., M. H. Ahmed, and E. A. Abbatte, "Epidemiology of bacterial pathogens associated with infectious diarrhea in Djibouti," Journal of Clinical Microbiology, vol. 28, no. 5, pp. 956-961, 1990.

[17] D. G. Newell, M. Koopmans, L. Verhoef et al., "Food-borne diseases-the challenges of 20 years ago still persist while new ones continue to emerge," International Journal of Food Microbiology, vol. 139, supplement 1, pp. S3-S15, 2010.

[18] A. Newton, M. Kendall, D. J. Vugia, O. L. Henao, and B. E. Mahon, "Increasing rates of Vibriosis in the United States, 1996-2010: review of surveillance data from 2 systems," Clinical Infectious Diseases, vol. 54, supplement 5, pp. S391S395, 2012.

[19] P. R. Murray, E. J. Baron, J. H. Jorgensen, M. L. Landry, and M. A. Pfaller, Manual of Clinical Microbiology, American Society for Microbiology, Washington, DC, USA, 6th edition, 1995.

[20] E. H. Lennette, A. Balows, W. J. Hausler Jr., and H. J. Shadomy, Manual of Clinical Microbiology, American Society for Microbiology, Washington, DC, USA, 4th edition, 1985.

[21] B. J. Stoll, R. I. Glass, M. I. Huq, M. U. Khan, H. Banu, and J. Holt, "Epidemiologic and clinical features of patients infected with Shigella who attended a diarrheal disease hospital in Bangladesh," Journal of Infectious Diseases, vol. 146, no. 2, pp. 177-183, 1982.

[22] M. J. Albert, M. Ansaruzzaman, K. A. Talukder et al., "Prevalence of enterotoxin genes in Aeromonas spp. Isolated from children with diarrhea, healthy controls, and the environment," Journal of Clinical Microbiology, vol. 38, no. 10, pp. 3785-3790, 2000.
[23] S. E. Gardner, S. E. Fowlston, and W. L. George, "In vitro production of cholera toxin-like activity by Plesiomonas shigelloides," Journal of Infectious Diseases, vol. 156, no. 5, pp. 720-722, 1987.

[24] G. Khaira and E. Galanis, "Descriptive epidemiology of Vibrio parahaemolyticus and other Vibrio species infections in British Columbia: 2001-2006," Canada Communicable Disease Report, vol. 33, no. 11, pp. 12-22, 2007.

[25] W. G. Hlady and K. C. Klontz, "The epidemiology of Vibrio infections in Florida, 1981-1993," Journal of Infectious Diseases, vol. 173, no. 5, pp. 1176-1183, 1996. 

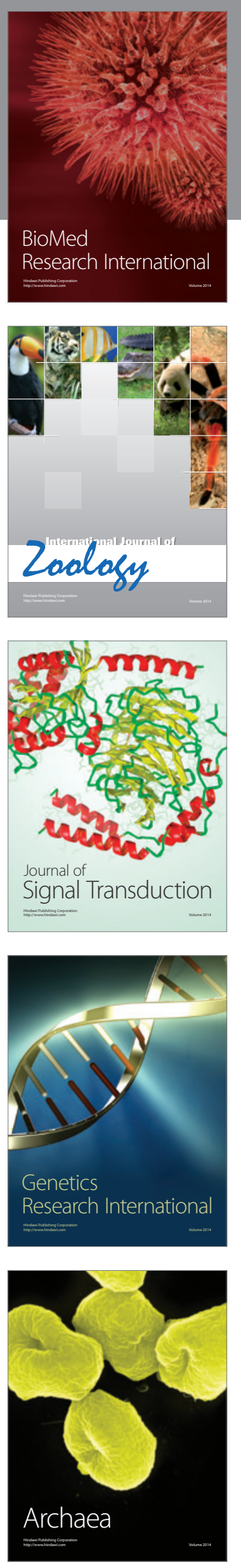
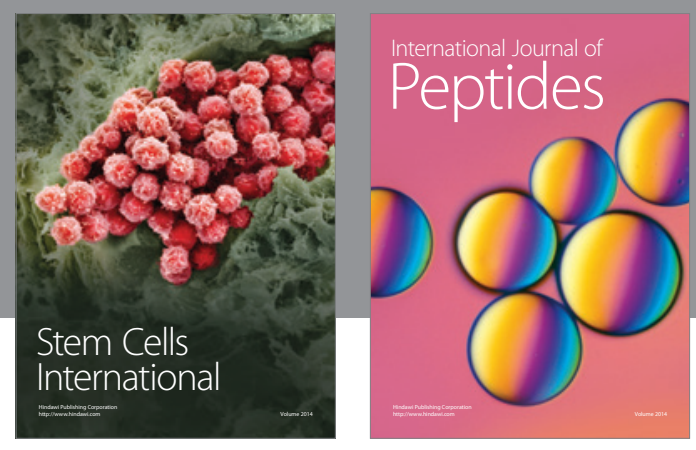

Submit your manuscripts at

http://www.hindawi.com
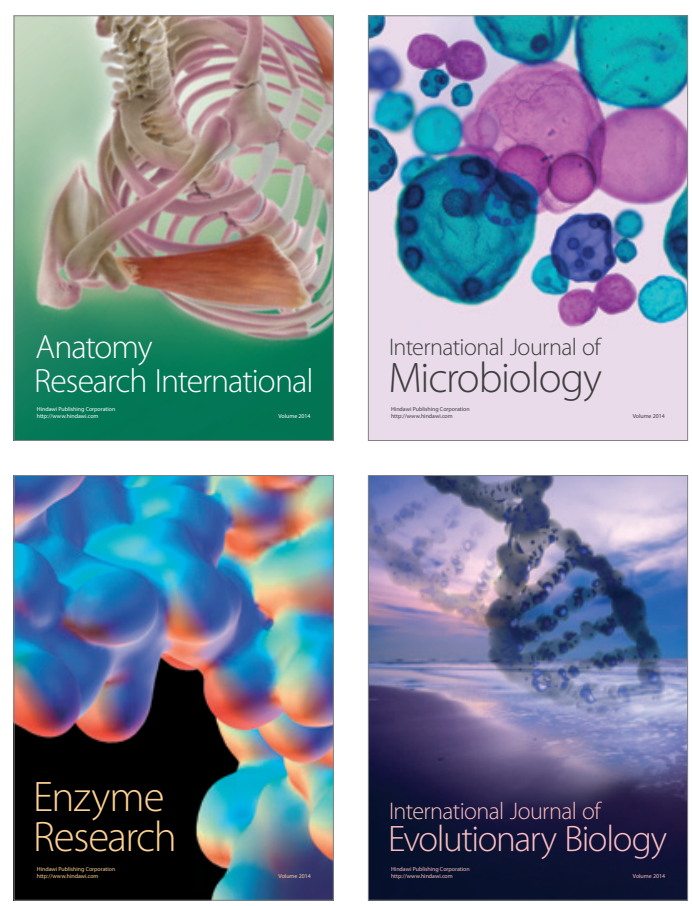
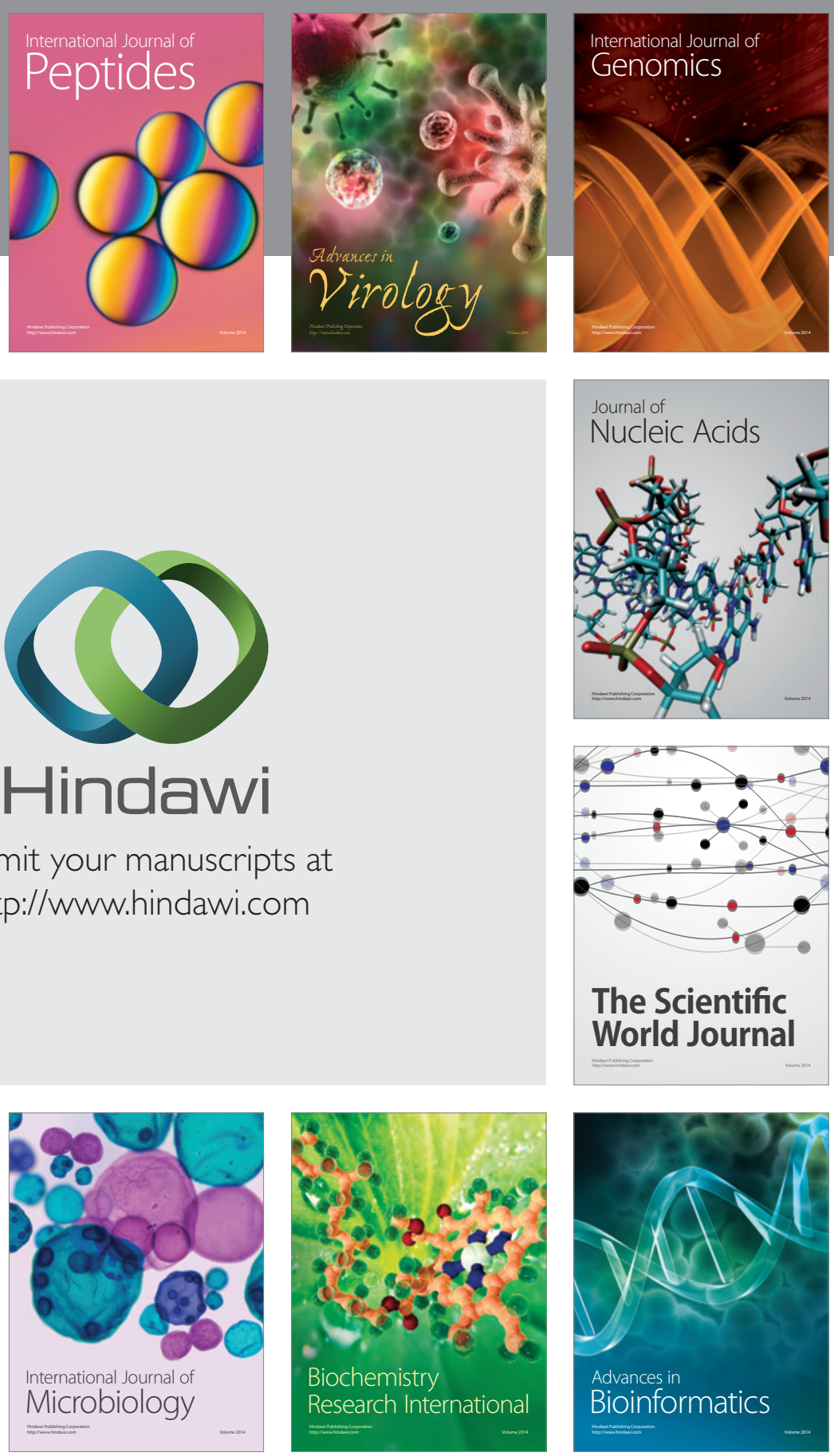

The Scientific World Journal
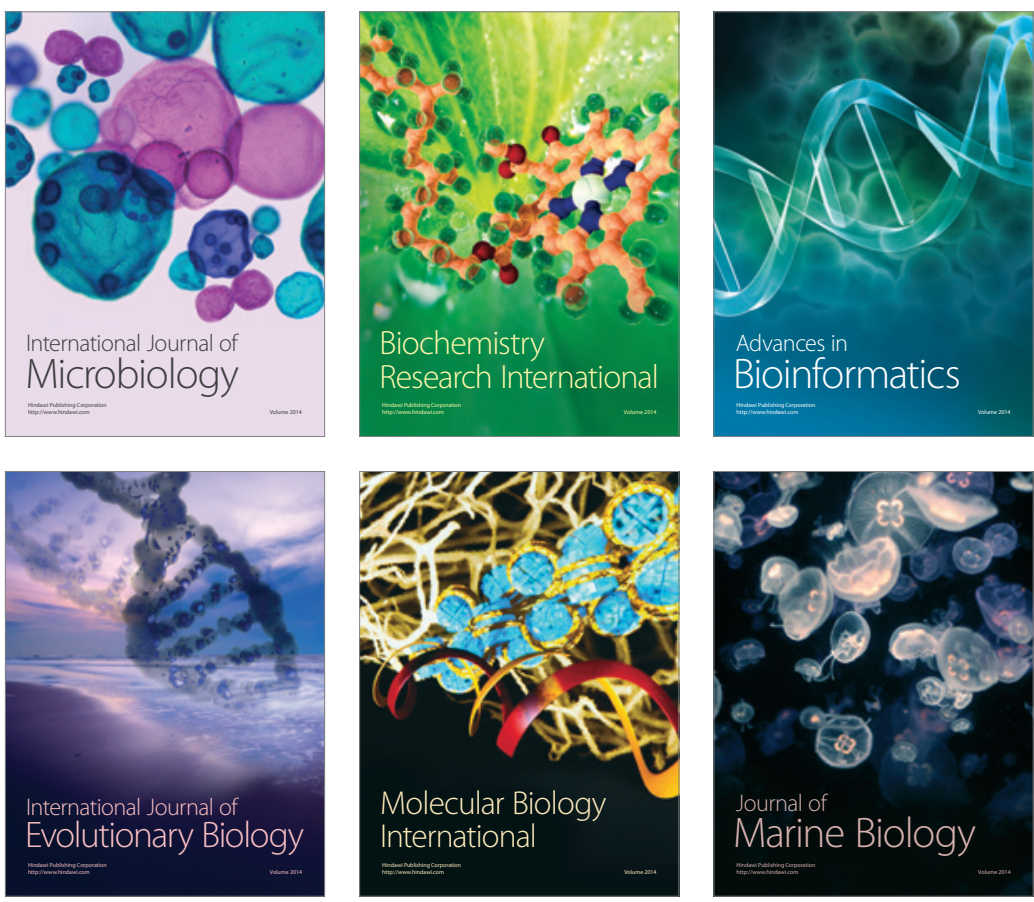